\title{
Plasmid-encoded trimethoprim resistance in multiresistant epidemic Salmonella typhimurium phage types 204 and 193 in Britain
}

\author{
E J THRELFALL, L R WARD, A S ASHLEY, B ROWE
}

\section{Summary and conclusions}

Multiresistant strains of Salmonella typhimurium phage types 204 and 193 appeared in calves in 1977 and then spread epidemically in cattle. Food poisoning is the main route by which drug-resistant strains from cattle are spread to man, and by the end of 1979 these two multiresistant strains had been identified in 290 cases of human salmonellosis in Britain. Trimethoprim-resistant $S$ typhimurium were rare until a strain of a new phage type, designated type 204c, spread in cattle in 1979. All isolations of type 204c were trimethoprim resistant. Trimethoprim had been used to treat cattle and this usage has probably contributed to the establishment of type 204c and the increased incidence of trimethoprimresistant strains.

The responsibility to prevent or control drug resistance in bovine $S$ typhimurium lies with the veterinary profession, and more stringent regulations governing the use of antibiotics in animals bred for food may be necessary.

\section{Outbreaks in cattle}

Cattle are the main source of Salmonella typhimurium in man in Britain, and the appearance of drug resistance in the bovine host is inevitably reflected in man by food poisoning. Multiresistant strains of $S$ typhimurium phage types 204 and 193 appeared in calves in Britain in 1977 and spread epidemically throughout bovine herds in 1978 and 1979. The type 204 strain with resistance to chloramphenicol, streptomycin, sulphonamides, and tetracyclines (R-type CSSuT) had been derived from type 49, which was common in bovines, by the acquisition of resistance plasmids. ${ }^{1}$ In turn the type 193 strain, with additional resistance to ampicillin and kanamycin (R-type ACKSSuT), had been derived from the type 204 strain of R-type CSSuT by acquisition of a plasmid coding for resistance to ampicillin, kanamycin, and streptomycin and for restriction of $S$ typhimurium typing phages. We suggested that the appearance of multiple drug resistance in these strains had been facilitated by the use of antimicrobial drugs in the treatment and prophylaxis of bovine salmonellosis.

\section{Outbreaks in man}

Human infections were recognised, and by the end of 1979 these two multiresistant strains had been identified in 290 cases of human salmonellosis in Britain (table). In most patients the symptoms were mild to moderate enteritis. In some cases, however, the diarrhoea was severe and persisted for several weeks; enteritis was reported as the cause of death in one elderly patient infected with type 204 of R-type CSSuT. Septicaemia occurred in seven patients, and one 3-year-old

Division of Enteric Pathogens, Central Public Health Laboratory, London NW9 $5 \mathrm{HT}$

E J THRELFALL, BSC, PHD, principal microbiologist

L R WARD, BSC, principal microbiologist

A S ASHLEY, FIMLS, medical laboratory scientific officer

B ROWE, MB, MRCPATH, director

Number of human infections with multiresistant Salmonella typhimurium types 204, 193, and 204c during 1977-9

\begin{tabular}{ccccc}
\hline Year & $\begin{array}{c}\text { Type 204 } \\
\text { (CSSuT) }\end{array}$ & $\begin{array}{c}\text { Type 193 } \\
\text { (ACKSSuT) }\end{array}$ & $\begin{array}{c}\text { Type 204c } \\
\text { ACSSTST or }\end{array}$ & Total \\
\hline 1977 & 37 & 4 & & 41 \\
1978 & 51 & 89 & 20 & 140 \\
1979 & 15 & 94 & 20 & 310 \\
\hline Total & 103 & 187 & &
\end{tabular}

Resistance symbols: $\mathrm{A}=$ ampicillin, $\mathrm{C}=$ chloramphenicol, $\mathrm{K}=$ kanamycin, $\mathrm{S}=$ streptomycin, $\mathrm{Su}=$ sulphonamides, $\mathrm{T}=$ tetracyclines, $\mathrm{Tm}=$ trimethoprim.

child died of septicaemia after a family outbreak of salmonellosis caused by the multiresistant type 193 strain. The mother and a younger child were also affected in this incident but suffered only enteritis.

\section{Development of trimethoprim-resistant strains}

Trimethoprim-containing products have been available for veterinary use in Britain since 1969. Trimethoprim-resistant strains of $S$ typhimurium, however, were rarely isolated from cattle before 1978 , and as recently as December 1978 Richards $e t a l^{2}$ reported that trimethoprim resistance was uncommon in strains of salmonellas examined at the Central Veterinary Laboratory (less than $0.3 \%$ in both 1976 and 1977). Trimethoprim resistance appeared in the multiresistant epidemic $S$ typhimurium strains in 1978, when type 204 of R-type CKSSuTTm ( $\mathrm{Tm}=$ trimethoprim) was identified in incidents among cattle on three farms and later in one human infection. Trimethoprim resistance in these strains was plasmid-encoded and carried on a plasmid of the $I_{1}$ compatibility group, which also coded for kanamycin and streptomycin resistance and production of colicin Ib (KSTmColIb). Three outbreaks of salmonellosis occurred in calves with type 193 of R-type ACKSSuTTm in 1978, and in these strains trimethoprim resistance was coded for by a plasmid of the $I_{2}$ group which also conferred streptomycin resistance.

In March 1979 a strain of $S$ typhimurium of R-type CSSuTTm caused an outbreak among calves on a unit of a calf-rearing complex in Somerset. The reactions of this strain with the $S$ typhimurium typing phages were similar to but not identical with those of a typical type 204 strain, and the new strain was designated type 204c. Characterisation of the plasmids and carried bacteriophages in the type 204c strain showed that the immediate progenitor was a strain of type 49 of R-type CSSuTTm, which was converted to type 204c by the acquisition of a small plaque, temperate bacteriophage (figure). In turn, this strain of type 49 had probably been derived from type 204 by loss of the property of typing phage restriction from the non-

Type 204

(CSSuT)

Type 49

(CSSuT)

Type 49

(CSSuTTm)

Derivation of type 204c (R-type CSSuTTm). 
autotransferring tetracycline resistance plasmid, which is type determining in strains of phage type 204. ${ }^{1}$ Trimethoprim resistance was coded for by the CSSuT-group $\mathrm{H}_{2}$ plasmid common to all type 204 strains of R-type CSSuT, and the additional gene sequence conferring resistance to trimethoprim was probably acquired by transposition from another plasmid.

By 31 December 1979 type 204c of R-type CSSuTTm had caused outbreaks affecting calves on at least 50 farms in the south and southwest of England and had been spread to Cambridgeshire and Yorkshire by the distribution of infected animals. Type 204c of R-type CSSuTTm had been identified in 19 human infections by 31 December 1979 and in one case caused septicaemia. Four infections were in farming families, but there was no obvious bovine connection in the remaining 15 cases, which suggests that the strain had already spread to the human food chain.

In the last three months of 1979 type 204c of R-type CSSuTTm acquired additional resistance to ampicillin and kanamycin, and type 204c of R-type ACKSSuTTm caused outbreaks among animals on six farms and was identified in one human infection. Ampicillin and kanamycin resistance in four bovine incidents and the human isolation was coded for by a non-autotransferring resistance determinant belonging to group 1 of non-autotransferring plasmids. ${ }^{3}$ In the remaining two bovine incidents type 204c of R-type CSSuTTm had acquired a KSTmCollb $R$ factor and an independent nonautotransferring resistance determinant that coded for resistance to ampicillin, streptomycin, and sulphonamides (ASSu).

\section{Implications and conclusions}

In a report of the incidence of trimethoprim resistance in bovine salmonellas between 1974 and $1976^{4}$ West and White concluded that "the present regulation and manner of use of veterinary trimethoprim products appears so far to have resulted in no resistance problems of real significance either in the treatment of animals or with regard to the exposure of humans to resistant strains." They particularly emphasised that all trimethoprim-containing products were recommended only for therapeutic use. During 1979 advertisements recommending trimethoprim-containing products for the treatment of calf enteritis appeared regularly in veterinary publications. Trimethoprim was used in attempts to treat animals infected with the multiresistant epidemic strains, and we have little doubt that such use resulted in the increased incidence of trimethoprimresistant $S$ typhimurium in cattle.

Continued surveillance of $S$ typhimurium types 204, 204c, and 193 in Britain has shown an ever-broadening range of drug resistance since 1977. The following R-types have now been identified in type 204, 204c, and 193 strains: SuT, CSSuT, CSSuTFu (Fu=furazolidone), CSSuTTm, CSSuTTmFu, AKSSuT, ACKSSuT, ACKSSuTFu, ACKSSuTTm, and ACKSSuTTmFu. This phenomenon must be a cause for great concern to doctors because when a strain of $S$ typhimurium resistant to ampicillin, chloramphenicol, kanamycin, streptomycin, sulphonamides, tetracyclines, trimethoprim, and furazolidone causes septicaemia or other extraintestinal lesions in a patient the choice of treatment is extremely limited.

The responsibility to prevent or control drug resistance in $S$ typhimurium in bovines in Britain lies with the veterinary profession. Such control measures may need the introduction of more stringent regulations governing the use of antibiotics in animals bred for food; clearly the current restrictions have failed.

\section{References}

1 Threlfall EJ, Ward LR, Rowe B. Spread of multiresistant strains of Salmonella typhimurium phage types 204 and 193 in Britain. $B r$ Med F 1978; ii:997.

2 Richards H, Datta N, Sojka WJ, Wray C. Trimethoprim-resistance plasmids and transposons in Salmonella. Lancet 1978;ii:1194-5.

${ }^{3}$ Smith HR. Studies of non-autotransferring plasmids in Escherichia coli and salmonellae. PhD thesis. University of London, 1975.

4 West B, White G. A survey of trimethoprim resistance in the enteric bacterial flora of farm animals. F $\mathrm{Hyg}$ (Camb) 1979;82:481-8.

(Accepted 1 April 1980)
ONE HUNDRED YEARS AGO We are indebted to Mr Jabez Hogg for the following particulars of a gallant action, led by an old and valued friend and former pupil of his, towards the end of last year, on the march to Cabul. It exhibits the usual spirit and dash of the officers of the Medical Service in the field, who, although described as non-combatants, are, as is well known, fully equal to any emergency, whether it be in leading an attack or attending on the wounded.

"On the last day of July, I applied to the Surgeon-General for employment in a cavalry regiment, and got a most favourable and flattering reply from him; and, within a month, was gazetted to the 12th Bengal Cavalry. So, in September, off I went, viâ Kohat Kurrum, to join my regiment, then with the advanced force at Cabul.... We were stopped at Kurrum by an attack of the Munguls, and finally got to Ali Kheyl, where we were surrounded by the enemy. I was, therefore, not in time to be present at the action of Charasiab; but, at the siege of Ali Kheyl, or rather the attacks on that cantonment, we had lots of doctors there, but not a single cavalry officer; so the general put me in command of the cavalry details (eighteen recruits and twenty-five old soldiers rejoining from leave of my own regiment, five of the 13th Bengal Lancers, and forty-nine of the 5th Punjab Cavalry). When the chief attack was at its fiercest (October 14th), a band of over one thousand Ghilzais were seen crossing the broad bed of the river to help the enemy; then General Gordon gave me command of all the mounted men, and told me to go at the lot, catching them in flank, and promised to back me with the 29th Punjab Infantry. We slipped down a ravine, the forty-three men of the 12th Bengal with me, and fifty-four of the others a little to the right (these men got stuck in a ravine and never joined me after all). When we got in sight, there were about six hundred crossing in detached parties of twelve, twenty, and thirty. I got our fellows into as good a line as possible, and we went at them and through them with a crash. Such a row! Their war-cry: 'Chavé-
Chavé Ul-Ul-Ul-Ullah' (Attack, attack for God), and our fellows' answer: 'Sir Kav Ki jai, Siri atral ki jai' (Victory for the great immortal, Victory for the Government); the rattle of the swords against their pikes and knives, and the shot from jezails, made up the most awful turmoil. I never knew before what battle was like. On the far side, we reformed, and in less than five minutes were again in the middle of them, long before they had time to load their jezails. We came through again with a smash, and they broke and fled in every direction, half going back, and about one hundred falling straight on to the 29th Punjab Infantry, who killed them nearly all. Thirty-five bodies were left on the spot; wounded not known. The attacks on the Shaturgardan having also failed, the road was open again to Cabul; so on we went, over the Shaturgardan and on to Cabul, arriving there on November 1st. I went with all the different expeditions sent about, and was at the fight at Tagao, when one company of the 67 th Regiment was hammered by the Safis. At Ali Kheyl, I had one man severely wounded-his hand was cut off by one blow with a knife; two wounded by sword-cuts; one by a pike-thrust; one horse shot dead, one stabbed to the heart, and six or seven cut with knives. No man killed. The 12th Bengal Cavalry was left to garrison Butkhak; but, when the outbreak took place and Shepur was surrounded, we made a night march and cut our way on to help and defend the cantonments, and for twelve days were night and day on duty; by day on patrol reconnaissance, and by night in the trenches on the East Birnaver ridge; and, on December 22nd, two hundred and fifty of the best mounted were picked out to cut a way through the enemy's brigade on the Liak Ferry ridge, and open a way for General Charles Gough's brigade. We did as we were ordered, losing in the action four men killed and wounded and twenty-four horses. This finished the fighting round about Cabul; and, on January 2nd, we were sent back to India to refit, recruit, and remount, and prepare for another forward movement." (British Medical fournal, 1880.) 